\title{
Basal Tryptase Levels Can Predict Clinical Severity in Hymenoptera Venom Anaphylaxis and Ischemic Cardiovascular Disorders
}

Farioli L ${ }^{1}$, Losappio $\mathrm{LM}^{2}$, Schroeder $\mathrm{JW}^{2}$, Preziosi $\mathrm{D}^{2}$, Scibilia $\mathrm{J}^{2}$, Caron $\mathrm{L}^{2}$, Nichelatti $\mathrm{M}^{3}$, Pastorello $\mathrm{EA}^{2}$

${ }^{1}$ Department of Laboratory Medicine, ASST Grande Ospedale Metropolitano Niguarda, Milan, Italy

${ }^{2}$ Department of Allergology and Immunology, ASST Grande Ospedale Metropolitano Niguarda, Milan, Italy

${ }^{3}$ Biostatistics Service, ASST Grande Ospedale Metropolitano Niguarda, Milan, Italy

J Investig Allergol Clin Immunol 2019; Vol. 29(2): 162-164 doi: 10.18176/jiaci.0363

Key words: Mast cells. Tryptase. Acute coronary syndrome. Major cardiovascular events. Hymenoptera venom allergy.

Palabras clave: Mastocitos. Triptasa. Síndrome coronario agudo. Eventos cardiovasculares graves. Alergia a veneno de himenópteros.

Mast cells play a significant role in allergic diseases and, along with macrophages, are important in the inflammatory process. Upon activation, mast cells degranulate and release mediators via different mechanisms in response to various stimuli. Allergic reactions are induced mainly by preformed mast cell mediators including histamine, tryptase, and chymase. Spikes in tryptase titers can be considered a marker of anaphylaxis [1,2], whereas increments in basal serum tryptase (BST) levels can be considered a marker of increased mast cell burden, as in mastocytosis [3], or of circumscribed inflammation, as in coronary atherosclerosis. In the follow-up of patients with previous acute coronary syndrome (ACS), we found that persisting elevated BST levels correlated with an increased risk of major adverse cardiovascular events (MACE) [4,5]. In other cases, high BST levels were shown to be biomarkers for the risk of severe allergic reactions to hymenoptera venom [6]. Given the heterogeneity of situations characterized by high BST levels, we aimed to detect specific values to formulate the prognosis or diagnosis of various clinical conditions.

We compared BST ranges in 2 clinical disorders. One population comprised patients with hymenoptera venom allergy (HVA) and a history of Mueller grade III and IV anaphylactic reactions [7]. The second population comprised patients with a history of ACS that we had previously described in 2 studies and now includes 9 new patients $[8,5]$. The statistical evaluation was based on a descriptive analysis, followed by inference using the Fisher exact test for categorical variables. We also performed the $t$ test for continuous variables and logistic regression followed by ROC analysis to dichotomize continuous variables with the aim of determining possible cut-off values.

A total of 579 patients (400 males/173 females; median age, 55 years [range, 5-92]) were included in this retrospective 


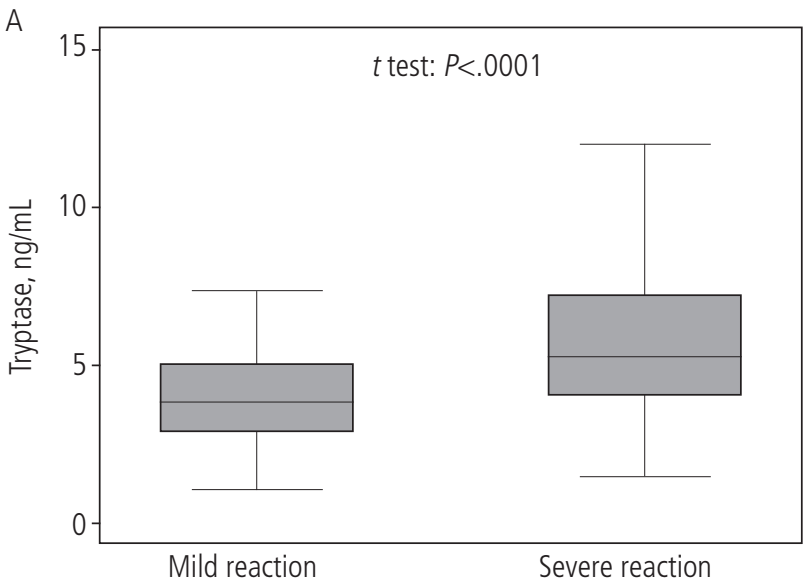

B

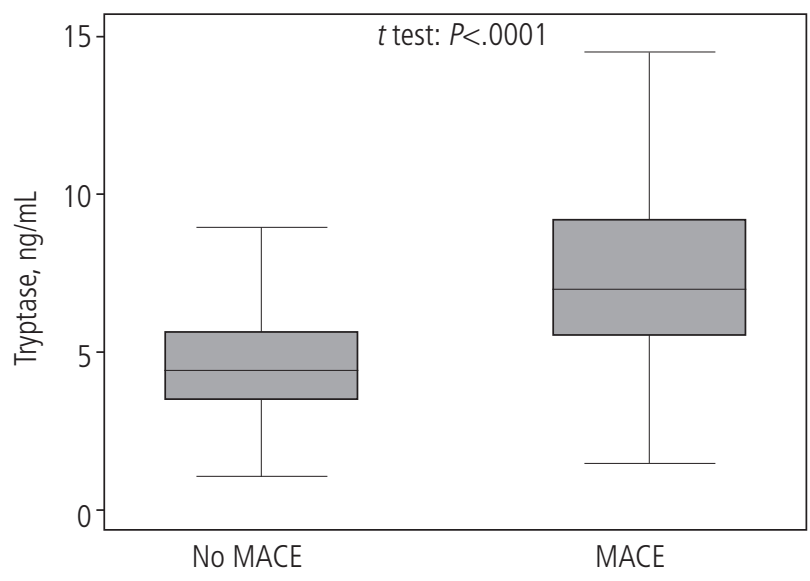

Figure. Comparison of tryptase levels. A, Mean tryptase values in HVA patients with mild and severe reactions. B, Mean tryptase values in MACE and non-MACE patients. HVA indicates hymenoptera venom allergy; MACE, major adverse cardiovascular events.

study. Of these, 365 had a history of HVA (246 males/119 females; mean [SD] age, 46.0 [18] years) and 214 had clinically diagnosed ACS (160 males/54 females; mean age, 65.0 [12.2] years). In the overall study population, the median BST level was $4.7 \mathrm{ng} / \mathrm{mL}$ (range, 1.0-47.7). We found a significant association between high BST levels and development of ACS and HVA (Mann-Whitney, $P<.0001$ ). We also found that any arbitrary unit increase $(+1 \mathrm{ng} / \mathrm{mL})$ in tryptase values corresponded to a $30 \%(95 \% \mathrm{CI}, 20 \%-40 \%$; $P<.001)$ increase in the odds of developing either HVA or MACE. The HVA population consisted of 203 patients with Mueller grade III and IV reactions (mean age, 45.0 [17.8] years) and 162 patients with Mueller grade I and II reactions (mean age, 43.8 [14.0] years); the mean tryptase value was $5.38(4.0 \mathrm{ng} / \mathrm{mL})$. We found that BST levels were significantly higher in patients with Mueller grade III and IV reactions than in patients with Mueller grade I and II reactions ( $t$ test, $P<.0001$ [Figure, A]), with a mean tryptase value of $6.4 \mathrm{ng} / \mathrm{mL}$ and $4.1 \mathrm{ng} / \mathrm{mL}$, respectively. Tryptase was associated with the occurrence of severe reactions inasmuch as any arbitrary unit increase $(+1 \mathrm{ng} / \mathrm{mL})$ in tryptase value corresponded to a $46 \%(95 \%$ CI, $29 \%-65 \%$; Wald test, $P<.0001)$ increase in the odds of Muller grade III and IV reactions. Eight of the
365 HVA patients had tryptase values $>13.8 \mathrm{ng} / \mathrm{mL}$, and all 8 patients had previously developed Muller grade IV reactions (Wald test, $P<.0001$ ). It is likely these patients were affected by some form of mast cell activation disease, as demonstrated by Bonadonna et al [9], who showed that tryptase values around $11 \mathrm{ng} / \mathrm{mL}$ in HVA patients can indicate expression of this disease. Moreover, we found that tryptase measurements may be used as a reliable method for stratifying risk among HVA patients. Patients classified as being at low risk of severe reactions had tryptase values of $<4 \mathrm{ng} / \mathrm{mL}(35.5 \%$ $[\mathrm{n}=50 / 141])$, those classified as intermediate-risk had tryptase values ranging from $\geq 4$ to $7.5 \mathrm{ng} / \mathrm{mL}(62.5 \%$ [n=107/172]), and those with a high risk had tryptase values $>7.5 \mathrm{ng} / \mathrm{mL}$ $(88.5 \%$ [ $\mathrm{n}=46 / 52])$. The significant effect exerted by BST on severe reactions was maintained after adjustment for age (Wald test, $P<.0001$ ). In the ACS population, 80 of the 214 patients had complex cardiovascular problems, and 134 had noncomplex problems. The ACS population was also divided into MACE patients ( $\mathrm{n}=54$; mean age, 62.0 [11.8] years) and non-MACE patients ( $\mathrm{n}=160$; mean age, 64.7 [11.2] years). In the overall ACS population, the mean tryptase value was $5.78[3.76] \mathrm{ng} / \mathrm{mL}$. Serum tryptase levels were significantly higher in complex patients than in noncomplex patients ( $t$ test, $P<.0001$ ), with mean tryptase values of $8.6 \mathrm{ng} / \mathrm{mL}$ and 4.1 $\mathrm{ng} / \mathrm{mL}$, respectively. Moreover, we found that mean tryptase values in MACE patients were significantly higher than in non-MACE patients ( $t$ test, $P<.0001$ [Figure, B]), with mean tryptase values of $8.18 \mathrm{ng} / \mathrm{mL}$, and $4.98 \mathrm{ng} / \mathrm{mL}$, respectively. The optimal tryptase range as a predictor of MACE was found to be $5-7 \mathrm{ng} / \mathrm{mL}$. The risk of developing MACE was significantly correlated with an increased BST value (Fisher exact test, $P<.0001)$. The significant effect exerted by BST on the MACE population did not vary after adjustment for age (Wald test, $P<.0001$ ). The optimal cut-off was set at $7.0 \mathrm{ng} / \mathrm{mL}$, with a $54 \%$ positive predictive value $(95 \% \mathrm{CI}, 39 \%-68 \%), 84 \%$ negative predictive value ( $95 \% \mathrm{CI}, 77 \%-84 \%), 50 \%$ sensitivity ( $95 \% \mathrm{CI}, 36 \%-64 \%)$, and $86 \%$ specificity ( $95 \% \mathrm{CI}, 79 \%-91 \%)$. In each of the 2 study populations, we found that in patients with the most severe clinical conditions, the tryptase level was approximately $7.0 \mathrm{ng} / \mathrm{mL}$.

The persistence of high BST levels suggests the possibility of monitoring these levels as a long-term marker of possible subsequent deterioration in patients with impaired heart conditions (eg, coronary atherosclerotic lesions). While the role of mast cells in ischemic heart disease can be more readily accepted, given the demonstration of their accumulation at the site of coronary atheromatous erosion [10], the reason for their proliferation in patients who go on to develop HVA is more difficult to explain, except for those cases that go on to develop systemic mastocytosis and mast cell activation syndrome. Our results seem to indicate that, despite the fact that HVA and ACS are completely different clinical conditions, they are characterized by a similar increase in tryptase levels, possibly in relation to an increase in concentrations of mast cells resident in vascular atherosclerotic lesions. The final severity of clinical features will then depend on other factors, such as the presence of specific hymenoptera venom $\operatorname{IgE}$ or previous extensive cardiovascular involvement. Tryptase is an important marker of vascular inflammatory involvement that could be useful in clinical practice for identifying patients 
who may go on to develop more severe clinical pictures, independently of the cause.

\section{Funding}

The authors declare that no funding was received for the present study.

\section{Conflicts of Interest}

The authors declare that they have no conflicts of interest.

\section{References}

1. Yoseph A, Mekori. The mastocyte: the "other" inflammatory cell in immunopathogenesis. J Allergy Clin Immunol 2004;114:52-7.

2. Treudler R, Kozovska Y, Simon JC. Severe immediate type hypersensitivity reactions in 105 German adults: when to diagnose anaphylaxis. J Investing Allergol Clin Immunol. 2008;18(1):52-8.

3. Akin C, Metcalfe DD. Occult bone marrow mastocytosis presenting as recurrent systemic anaphylaxis. J Allergy Clin Immunol. 2003;111:206.

4. Pastorello EA, Farioli L, Losappio LM, Morici N, Di Biase M, Nichelatti $M$, et al. Serum tryptase detected durgin acute coronary syndrome is significantly related to the development of major cardiovascula eventes after 2 years. Clin Mol Allergy. 2015;13(1):14.

5. Morici N, Farioli L, Losappio LM, Colombo G, Nichelatti M, Preziosi $D$, et al. Mast cells and acute coronary syndromes: relationship between serum tryptase, clinical outcome and severity of coronary artery disease. Open Heart. 2016;3(2)e000472.

6. Kucharewicz I, Bodzenta-Lukaszyk A, Szymanski W, Mroczko B, Szmitkowski M. Basal serum tryptase level correlates with severity of hymenoptera sting and age. J Investig Allergol Clin Immunol. 2007;17(2):65-9.

7. Mueller HL J. Diagnosis and treatment of insect sensitivity. Asthma Res. 1966;3:331-3.

8. Pastorello EA, Morici N, Farioli L, Di Biase M, Losappio LM, Nichelatti $M$, et al. Serum tryptase: a new biomarker in patients with acute coronary syndrome? Int Arch Allergy Immunol. 2014;164:97-105.

9. Bonadonna P, Perbellini O, Passalacqua G, Caruso B, Colarossi $\mathrm{S}$, Dal Fior D, et al. Clonal mast cell disorders in patients with systemic reactions to Hymenoptera stings and increased serum tryptase levels. J Allergy Clin Immunol. 2009;123(3):680-6.

10. Kovanen PT, Kaartinen $M$, Paavonen $T$. Infiltrates of activated mast cells at the site of coronary atheromatous erosion or rupture in myocardial infarction. Circulation. 1995;92(5):1084-8.

Manuscript received October 11, 2018; accepted for publication December 11, 2018.

Elide Anna Pastorello Allergologia e Immunologia ASST Grande Ospedale Metropolitano Niguarda

Piazza Ospedale Maggiore, 3 Milan 20162, Italy

E-mail: elide.pastorello@ospedaleniguarda.it 